\title{
Modeling of the Behavior of a Deep Groove Ball Bearing in Its Housing
}

\author{
Ayao E. Azianou ${ }^{1,2}$, Karl Debray ${ }^{1}$, Fabrice Bolaers ${ }^{1}$, ${\text { Philippe } \text { Chiozzi }^{2} \text {, Frédéric Palleschi }}^{2}$ \\ ${ }^{1}$ Groupe de Recherche en Sciences de l’Ingénieur, Université de Reims Champagne Ardenne, EA 4694 URCA, Moulin de la Housse, \\ 51687 Reims Cedex 2, France \\ ${ }^{2}$ Valeo Electric Systems, 2 Rue André Boulle, 94000 Créteil, France \\ Email: a.azianou@gmail.com, karl.debray@univ-reims.fr
}

Received August 2013

\begin{abstract}
Load distribution in deep groove ball bearing has been studied in this work. A deep groove ball bearing model is proposed basing on geometry specific measurement. Two approaches (finite element method and semi-analytical) have been used to determine the distribution of an external radial force applied. These two approaches have been compared in terms of computation time and precision. At the second point, a deformable complex bearing housing has been integrated in the FEM ball bearing model to assess the influence of its deformation on load distribution.
\end{abstract}

Keywords: Ball Bearing; Finite Element; Semi-Analytical; Load Distribution; Housing

\section{Introduction}

Automotive alternators are rotating machines whose main role is to convert the mechanical energy of rotation into electrical energy for powering electrical and electronic components of the car. With the evolution of technology, new generations of alternators have been developed. These alternators have complex shapes and are equipped with stop-and-start systems to reduce noise, fuel consumption and the emission of greenhouse gases. An alternator is mainly composed of a stator and a rotor guided in rotation by two ball bearings. The transfer of loads from one ring to another is possible by means of the balls in contact with the rings. Load distribution in bearings is an important factor in the proper functioning of the ball bearing and its fatigue lifetime estimation. Depending on the type of external load, all the balls don't have the same contribution to the load transfer. Another important parameter involved in the load distribution is the internal clearance within the ball bearing.

Several authors have worked on load distribution problem. The first work was done by Stribeck [1] for external radial loading. He has determined in his formulation the maximum force on a ball. Although this formulation has been used for a long time to calculate the static bearing capacity, it does not explicitly consider the value of the clearance. Sjovall [2] established a formulation taking into account the value of the clearance where the maximum force is a function of an integral that holds his name.
Jones [3], based on the Hertz contact theory [4] proposed an analytical approach to determine the relative motion of the rolling over rings. This approach was improved by Harris and was called Jones-Harris method (JHM) [5]. The relative displacements at the contact ballrings due to external forces were determined by NewtonRaphson method. From the relation between force and displacement, the forces are obtained from the displacements obtained by Hertz formulation. Other authors used Finite Element Method (FEM) to solve the problems of contact within the bearing and determine load distribution. By using the finite element method to determine coefficients used in load-displacement relation, Yuan Kang et al. [6] modified the method of Jones-Har- ris which was called modified Jones-Harris method (MJHM). Bourdon et al. [7] replaced, in a modeling of deep groove ball bearings, balls by specific elements to study the bearing behavior.

Most of these studies considered that the bearings are mounted in a rigid housing. This assumption is not realistic when we consider the case of a new generation of alternator where the housing is complex and deformable. This paper assesses the influence of housing deformation on load distribution in the bearing by two different approaches: a finite element approach and a semi-analytical approach where the rolling elements are replaced by user elements. A prior study has been done by using these two approaches in the case of rigid housing.

The geometry of ball bearing is important in load distribution modeling, especially curvature radii of the 
raceways of the inner and outer ring. These values are not indicated by bearing suppliers and they are difficultly determinable by conventional measurement methods. We have developed a new methodology to measure these values using a three-dimension measuring machine.

\section{Method for Determining Deep Groove Ball Bearing Geometry}

\subsection{Removing Bearing Component to Access the Raceway}

The method is to reconstruct the geometry and determine the radii of curvature from points equally distributed on the raceway. Because of the fact that ball bearings deep groove are rigid (non-demountable), a way to access raceways has to be found. The ball bearings are divided in two parts (Figure 1) by an electrical discharge machining (EDM). EDM was used because of its advantages. Cutting is performed by removing small particles of the material of electric arc between tool and workpiece. There is no contact between the workpiece and the tool, so no deformation of the bearing which may influence the measurement results.

\subsection{Determination of Ball Bearing Geometry}

The parts of bearing ring are mounted and locked in a vee fixed on the magnetic table of the measuring machine. Bearing raceway has a shape of a half torus with a small and a big radius. The plane in which points are probed the big curvature radius is the median plane to planes P1 and P2 from the ring shoulder (Figure 2). The small radius is scanned in the plane perpendicular to the median plane. From the probed points coordinates, the curvature radii are obtained by the least squares method.

With the values obtained by measurement, the geometry of the bearing is reconstructed numerically.

\section{Modeling of Ball Bearing Behavior}

A ball bearing is composed by the outer ring, inner ring, the balls, and the cage whose role is to maintain the distance between balls. In the present analysis the effect of the cage is neglected. During loading, balls in contact with the rings deform both inner and outer rings. Because of the fact that the contact surfaces in ball bearing are not known, contact problem is complex. Hertz was the first to solve the problem by considering contact between two ellipsoids. He established a relation between load and displacement. Based on his work, the relation between the displacement on each ball and the force that produces it is given by:

$$
Q=K \delta^{s}
$$

where $\delta$ is the relative approach between the two rings,

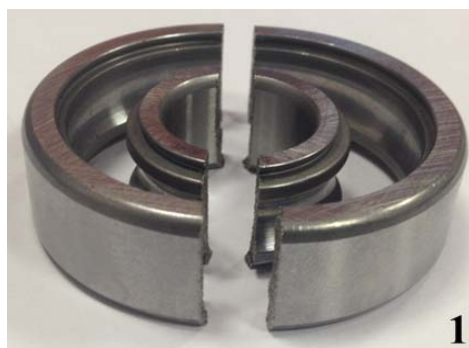

(a)

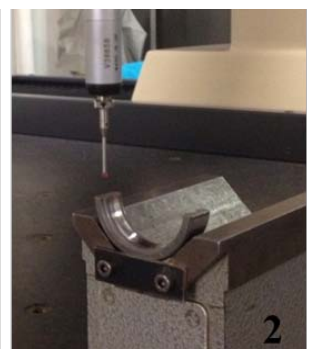

(b)
Figure 1. Determination of bearing geometry. (a) Bearing disassembled; (b) Palpating rings.

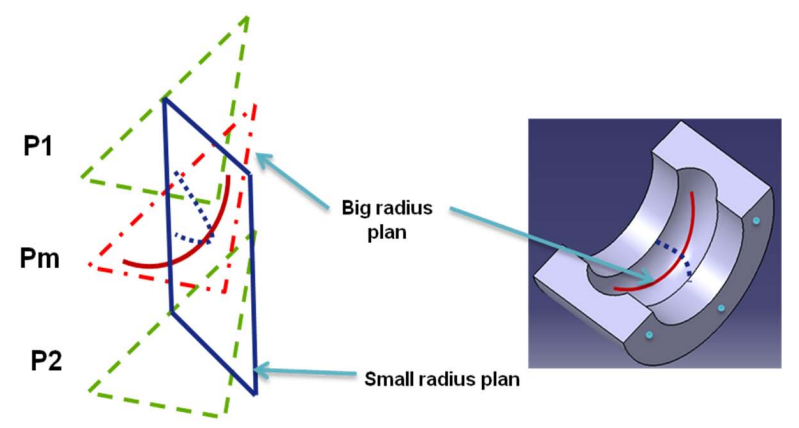

Figure 2. The principle of probing points

$K$ is the rigidity of the ball and raceway contact and $\mathrm{s}$ is the load deflection exponent. $s$ value is $3 / 2$ for ball bearing. The rigidity is related to the raceway geometry and material property [8].

The load distribution in a ball bearing is an important parameter in fatigue lifetime calculation. In mechanisms, bearings can be submitted to many solicitations: radial, axial, moments or combination of axial and radial loads. Rolling elements (balls) don't behave in the same way. In the case of radial loading, only some of the balls are under load $[1,9]$.

In the configuration showed in Figure 3, the number of balls under load is given by:

$$
m=2 n+1
$$

With,

$$
\mathbf{n}=\mathbf{I N T}\left(\frac{\mathbf{z}-1}{4}\right)
$$

where $\mathrm{n}$ is the parameter that designates the number of pairs of balls transferring load in addition to the ball 1 (Figure 3) and $\mathrm{z}$ is the number of balls. Balls are distributed equitably on the raceway circumference and the angle between balls is $\beta$.

$$
\beta=\frac{2 \pi}{z}
$$

By using static equilibrium and projecting load on each ball in the three directions, the relation between loads is given by: 


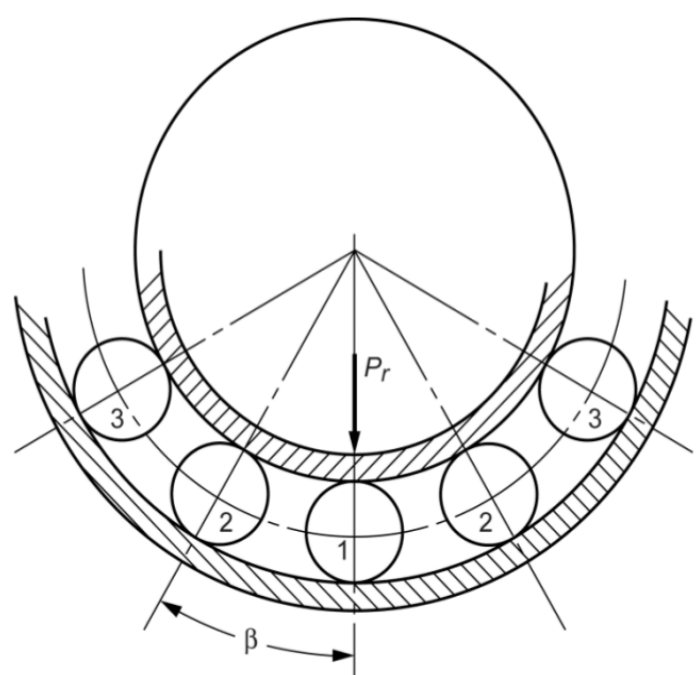

Figure 3. Bearing subjected to external load $P_{r}[10]$.

$$
\begin{aligned}
& P_{r}=P_{1}+2 P_{2} \cos \beta+2 P_{3} \cos 2 \beta+\cdots+ \\
& 2 P_{n} \cos n \beta
\end{aligned}
$$

Loads and displacements are related according to hertz theory by:

$$
\frac{P_{n}}{P_{1}}=\left(\frac{\delta_{n}}{\delta_{1}}\right)^{3 / 2}
$$

And

$$
\delta_{j}=\delta_{1} \cos j \beta
$$

with $j=2,3, \ldots, n+1$.

So

$$
P_{j}=P_{1}(\cos [(j-1) \beta])^{3 / 2}
$$

With (8), (5) becomes:

$$
\begin{aligned}
& P_{r}=P_{1}\left[1+2(\cos \beta)^{2.5}+2(\cos 2 \beta)^{2.5}+\ldots\right. \\
& \left.+2(\cos n \beta)^{2.5}\right]=P_{1}[Q]
\end{aligned}
$$

$P_{1}$ is the maximum load on ball,

$$
P_{r}=P_{\max }[Q]
$$

These relations are valid for ball bearings with zero clearance submitted to radial load. The maximum load is deducted by the relation:

$$
P_{\text {max }}=\frac{P_{r}}{Q}=\frac{S_{t} P_{r}}{Z}
$$

$S_{t}$ is called Stribeck Number, and it is around 4.37. Although it is valid for bearing with zero clearance mounted in a rigid housing, Stribeck suggested attributing to his constant a value of 5.0 to take into consideration the presence of clearance.

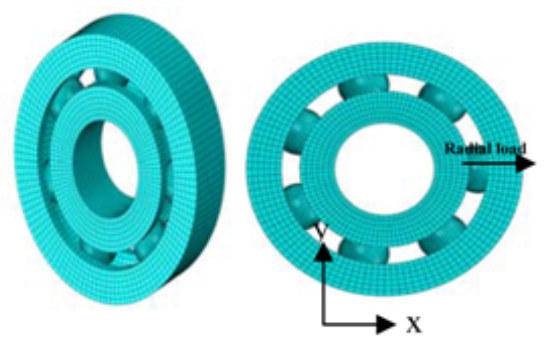

Figure 4. 3D bearing model loaded.
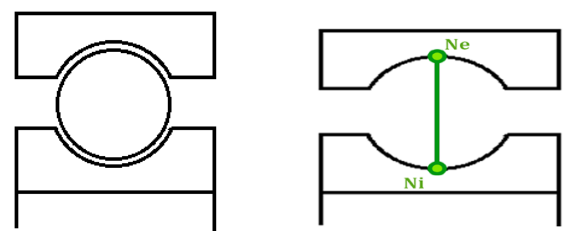

Figure 5. Ball replaced by "ball element".

Stribeck relation was one of first mathematical formulations that deals with load distribution in bearings. Other formulations were developed; all of them consider in its assumptions a rigid housing. Realistic models that consider housing deformation are proposed. First, two approaches are studied in the case of rigid housing and compared to mathematical formulations. Secondly, the deformable housing is integrated in the model to evaluate its deformation influence.

\subsection{Finite Element Method Model}

A three-dimension FEM bearing model is used for the determination of load distribution. The model consists of an inner ring, an outer ring and seven balls. A radial external load of $5000 \mathrm{~N}$ is applied on inner ring. The geometry of the bearing was obtained from the method described in 2.

Assumptions: The material of the bearing is applied in the elastic area; a frictionless contact between the balls and the bearing rings is considered. The influence of the cage is neglected. A quasi-static analysis is considered. Because of low deformation of balls, they are represented by rigid spheres.

The main steps of the analysis of bearing contact are: (1) 3D construction using ball bearing geometry, (2) Definition of material properties of components: (Table 1), (3) Definition of contact properties (4) Application of the necessary boundary conditions and loading, (5) Resolution of contact problem, (6) Treatment of results.

FEM ball bearing model has 89134 node and 25354 elements. Materials properties for balls and rings are defined in Table 1.

\subsection{Semi-Analytical Approach}

The approach is based on Bourdon and De Mul's mod- 
els. In this approach, balls are replaced by two nodes elements that properties are computed. Outer and inner rings are meshed like in finite elements method. Because of the fact that solid elements have only three degrees of freedom (3 translations), shell elements are merged on raceways to enable rotation degrees of freedom of "ball elements". Five degrees of freedom (3 translations and 2 rotations) are considered, the rotation around the shaft is free.

The global static equilibrium is reached when the residual vector $\{R\}$ is cancelled. In a revolving machine, the bearings have a nonlinear behavior due to the Hertz contact, but other components essentially have linear behavior, so the internal force vector can be separated into two parts:

$$
\{R\}=\left\{F_{\text {int }}\right\}-\left\{F_{\text {ext }}\right\}=\left\{F_{\text {int }}^{L}\right\}+\left\{F_{\text {int }}^{N L}\right\}-\left\{F_{\text {ext }}\right\}=\{0\}
$$

With $F_{\text {int }}$ and $F_{\text {ext }}$ are internal and external forces, $F_{\text {int }}^{N L} \quad F_{\text {int }}^{L}$ are internal linear and nonlinear forces. Newton-Raphson method is used to solve this non-linear system, the :

$$
\begin{gathered}
{\left[K_{T}\right]\{\Delta \mathbf{u}\}=\{R\}} \\
\left\{u^{i+1}\right\}=\left\{u^{i}\right\}+\{\Delta u\}
\end{gathered}
$$

where $\left[K_{T}\right]$ is global tangent stiffness matrix:

$$
\left[K_{T}\right]=-\left[\frac{\partial\{R\}}{\partial u}\right]=-\left\{\left[K_{T}^{L}\right]+\frac{\partial\left\{F_{\mathrm{int}}^{N L}\right\}}{\partial u^{N L}}\right\}
$$

The steps to solve the problem of this approach are defined in Figure 6. At each iteration increment, the

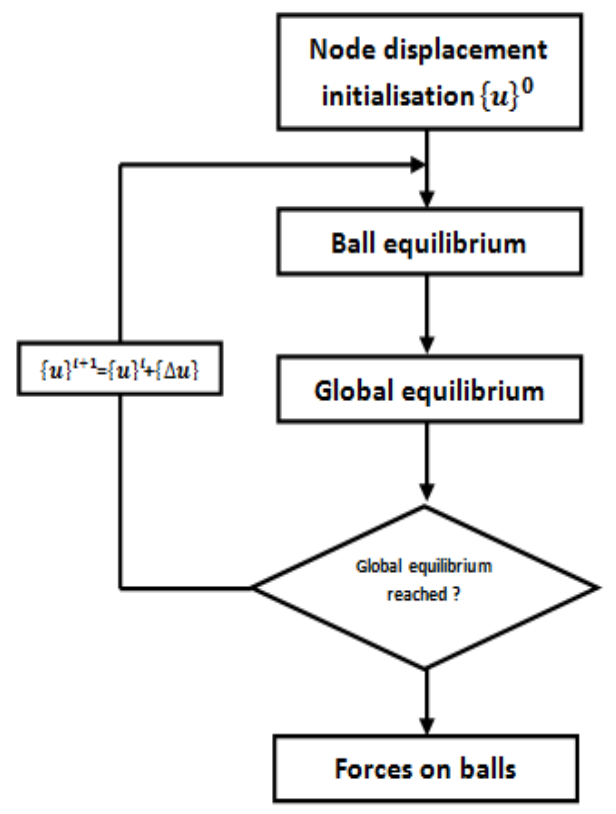

Figure 6. Flow chart of load determination of deep groove ball bearings.
Table 1. Material properties for ball bearing.

\begin{tabular}{ccccc}
\hline \multirow{2}{*}{$\begin{array}{c}\text { Bearing } \\
\text { components }\end{array}$} & Material & $\begin{array}{c}\text { Young module } \\
\text { (Mpa) }\end{array}$ & $\begin{array}{c}\text { Density } \\
\left(\mathrm{kg} / \mathrm{m}^{3}\right)\end{array}$ & $\begin{array}{c}\text { Poisson } \\
\text { ratio }\end{array}$ \\
\cline { 2 - 5 } & Bnner and \\
$\begin{array}{c}\text { outer ring } \\
\text { Balls }\end{array}$ & Bearing steel & 210000 & 7800 & 0.285 \\
\hline
\end{tabular}

obtained displacement vector $\{u\}$ allows to compute the bearing's tangent stiffness matrix. The linear part of the stiffness matrix does not change in course of iterations. The displacement of elements is initialized in the beginning of the analysis. The equilibrium of each ball element is solved, and their stiffness matrices are calculated.

The methodology is used to study load distribution in a deep ball bearing. Rings geometry is determined by method used in 2. A radial load is applied in the

\subsection{Housing Deformation Influence: FEM Approach}

Previous analyses are valid for rigid housing. Alternator bearing housing (Figure 7), due to his complex shape may influence the load distribution. It has been integrated numerically in FEM model to evaluate its deformation on load distribution in the deep groove bearing. FEM method is chosen for this study to be closer to reality because balls are geometrically represented.

The analysis is focused on the radial loading case because the front bearing of the alternator is essentially loaded radially. The model consists of a deep groove ball bearing and alternator housing. The connection between the outer ring and the housing is complete. The appropriate boundary conditions are applied. The external load of $5000 \mathrm{~N}$ is radially applied in the geometric center of the bearing (Figure 8).

Materials properties are defined in Table 2. The model consists of 121425 nodes and 396840 elements.

\section{Results and Discussion}

Load distribution obtained by the two approaches has been compared to analytical formulation in rigid housing case. Among seven balls, only three participate in the load transfer. This is in accordance with literature formulation. A radar chart (Figure 9) presents radial loads on three balls. The maximal load is on ball number 0 .

For the two approaches, we note that results are consistent (Table 3) and closer to analytical formulation, deviation is less than 3 percent when we compare the two approaches. The semi-analytical approach presents an advantage of computation time. It is four times faster than FEM approach. 


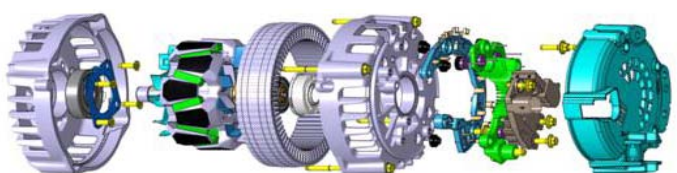

Figure 7. Schematic view of automotive alternator.

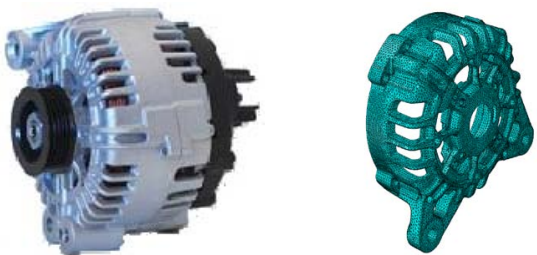

Figure 8. Complex shape of bearing housing.

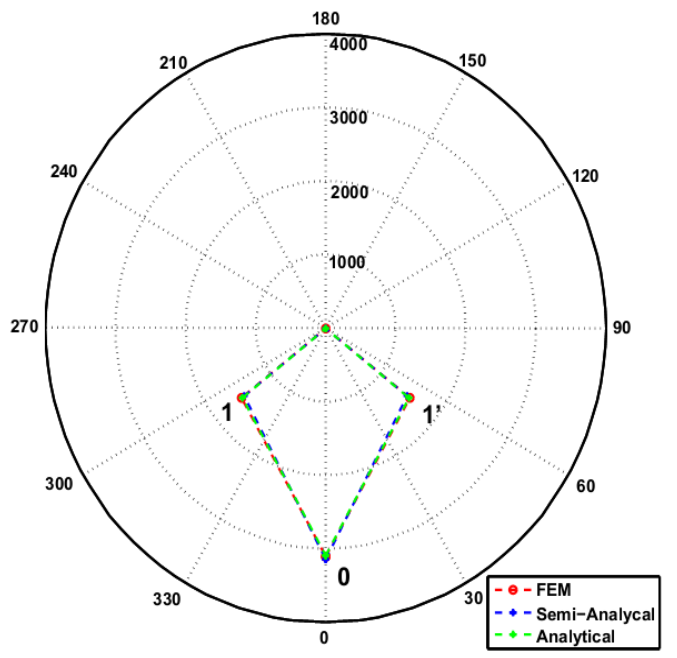

Figure 9. Load distribution.

Table 2. Material properties for ball bearing and its housing.

\begin{tabular}{ccccc}
\hline \multirow{2}{*}{$\begin{array}{c}\text { Bearing } \\
\text { components }\end{array}$} & Material & $\begin{array}{c}\text { Young module } \\
\text { (Mpa) }\end{array}$ & $\begin{array}{c}\text { Density } \\
\left(\mathrm{kg} / \mathrm{m}^{3}\right)\end{array}$ & $\begin{array}{c}\text { Poisson } \\
\text { ratio }\end{array}$ \\
\cline { 2 - 5 } & Bearing steel & 210,000 & 7800 & 0.285 \\
$\begin{array}{c}\text { Inner and } \\
\text { outer ring }\end{array}$ & Bearing steel & 210,000 & 7800 & 0.285 \\
Balls & Aluminium alloy & 70,000 & 2700 & 0.3 \\
\hline
\end{tabular}

FEM approach is compared for two cases (Figure 10): rigid and deformable housing. Although the maximal load is on ball number 0 , external radial load is not distributed by the same way compared to rigid housing (Table 4).

The complexity of housing shape and its material properties (aluminum alloy) lead a load distribution different from a rigid housing. Housing influence on load distribution can be an important factor that affects bearing durability estimation.

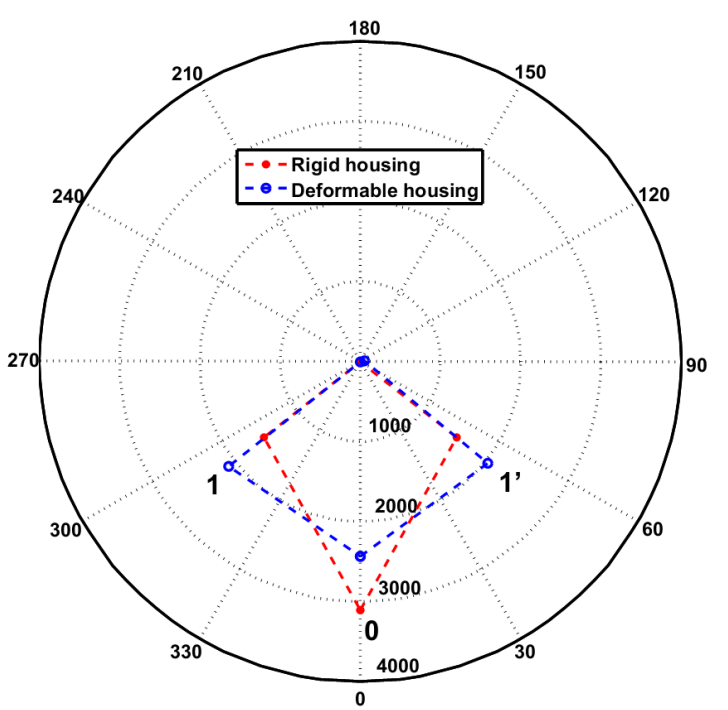

Figure 10. Load distribution considering deformable housing

Table 3. Loads on balls values.

\begin{tabular}{ccccc}
\hline \multirow{3}{*}{ Balls } & \multicolumn{4}{c}{ Radial loading, } \\
& Clearance $=0.011 \mathrm{~mm}(\operatorname{Pr}=5000 \mathrm{~N})$ \\
\hline Ball 0 & 3102.50 & 3142.51 & -1.28 & 3098.07 \\
Ball 1 & 1529.52 & 1489.61 & 2.61 & 1525.23 \\
Ball 1' & 1529.52 & 1489.60 & 2.61 & 1525.23 \\
\hline
\end{tabular}

Table 4. Influence of housing deformation.

\begin{tabular}{ccc}
\hline \multirow{2}{*}{ Balls } & \multicolumn{2}{c}{ Radial loading, } \\
& Clearance $=0.011 \mathrm{~mm}(\mathrm{Pr}=5000 \mathrm{~N})$ \\
\cline { 2 - 3 } & Rigid housing & $\begin{array}{c}\text { Deformable housing } \\
\text { FEM }\end{array}$ \\
\hline Ball 0 & 3102.50 & 2435.72 \\
Ball 1 & 1529.52 & 2032.2 \\
Ball 1' & 1529.52 & 2100.06 \\
\hline
\end{tabular}

\section{Conclusions}

In this study, two approaches: a FEM and a semi analytical approach are used for load distribution calculation in statically radial loading. These results are consistent and closer to analytical formulations in the case of rigid housing. Semi-analytical approach is seen to be cheaper in term of computation time.

Using FEM, a complex deformable housing is numerically integrated in a ball bearing to study the load distribution considering. The numerical results show that housing deformation has effect on load distribution. Because load distribution is an important parameter in ball bearing durability, the housing has to be considered in 
fatigue lifetime analysis.

\section{REFERENCES}

[1] R. Stribeck, "Ball Bearings for Various Loads," Transactions of the ASME, Vol. 29, 1907, pp. 420-463

[2] H. Sjoväll, "The Load Distribution within Ball and Roller Bearings under Given External Radial and Axial Load," TekniskTidskrift, Mek., h.9, 1933.

[3] A. B. Jones, "A General Theory for Elastically Constrained Ball and Radial Roller Bearing under Arbitrary Load and Speed Conditions,” Journal of Basic Engineering, Vol. 82, No. 2, 1960, pp. 309-320.

[4] H. Hertz, "Uber die Beruhrung Fester Elastischer Korper (On the Contact of Elastic Solids)," J Reine Angew Math, Vol. 92, 1882, pp. 156-171.

[5] T. A. Harris, "Rolling Bearing Analysis," Wiley, New York, 2001.

[6] Y. Kanga and P.-C. Shen, "A Modification of the JonesHarris Method for Deep-Groove Ball Bearings,” Tribol- ogy International, Vol. 39, No. 11, 2006, pp. 1413-1420. http://dx.doi.org/10.1016/j.triboint.2005.12.005

[7] A. Bourdon, J. Rigal and D. Play, "Static Rolling Bearing Models in a C.A.D. Environment for the Study of Complex Mechanisms: Part II-Complete Assembly Model,” Journal of Tribology, Vol. 121, No. 2, 1999, pp. 215-223. http://dx.doi.org/10.1115/1.2833924

[8] M.C. Ricci, "Internal Loading Distribution in Statically Loaded Ball Bearings Subjected to a Centric Thrust Load: Alternative Approach," World Academy of Science, Engineering and Technology, Vol. 65, 2010, pp. 641-649.

[9] "Effect of Internal Clearance on Load Distribution and Life of Radially Loaded Ball and Roller Bearings,” 65th Annual Meeting and Exhibition Sponsored by the Society of Tribologists and Lubrication Engineers (STLE), Las Vegas, Nevada, 16-20 May 2010.

[10] F. B. Oswald and E. V. Zaretsky and W. J. Anderson, "Rolling-Element Bearings," In: E. E. Bisson and W. J. Anderson, Eds., Advanced Bearing Technology, NASA/ SP-38, 1964, pp. 164-168. 